\title{
EXPERIÊNCIA DO PROGRAMA DE CONTROLE DA TENÍASE E DA CISTICERCOSE NO ESTADO DO PARANÁ
}

\author{
R.LF. GUSSO ${ }^{1}$; V.T. SOCCOL ${ }^{2}$; N.J. CAMARGO ${ }^{3}$; L.R. SILVA ${ }^{3}$
}

${ }^{1}$ Mestrando do Curso de Pós-Graduação em Ciências Veterinárias - Universidade Federal do Paraná/ Centro de Produção e Pesquisas de Imunobiológicos. ${ }^{2}$ Professora Doutora do Departamento de Patologia Básica da Universidade Federal do

Paraná. ${ }^{3}$ Secretaria de Estado da Saúde do Paraná/Departamento de Saúde Comunitária-Universidade Federal do Paraná.

Introdução: A Cisticercose é considerada a mais freqüente e grave das infecções parasitárias do sistema nervoso humano. A enfermidade é severa, incapacitante e ocasionalmente fatal. Segundo a Força Tarefa Internacional para erradicação de Doenças, do Central Control Disease, 1993, Atlanta, USA, existem 50 milhões de casos no mundo com 50.000 óbitos devido ao complexo Teníase/Cisticercose. Atinge elevados índices na população paranaense, sendo endêmica e até hiperendêmica em algumas localidades, pois tem, segundo a Organização Mundial da Saúde, a presença de pacientes cuja causa mortis é Cisticercose, $1 \%$ de positividade para Taenia sp e mais de $5 \%$ das carcaças suínas parasitadas por Cysticercus cellulosae. No Paraná, para Neurocisticercose em 54.694 tomografias realizadas em 9 regionais de saúde no período de 1988 a 1992. estudos epidemiológicos em serviços de neurologia apontam percentuais de positividade de 3,4 a 19,32\%. O número de casos notificados e confirmados no Estado de 1993 a 1997 foi de 844. O coeficiente de incidência(100.000) de Neurocisticercose foi de 1,13, 1,62, 3,52, 1,34, 1,92 de 1993 a 1997 respectivamente. O coeficiente de letalidade de Neurocisticercose no Paraná de 1993 a 1997 foi respectivamente de 31,$63 ; 11,97 ; 2,93 ; 14,87 ;$ e 10,22 . Segundo o número e o percentual de casos de Neurocisticercose, segundo idade no Paraná de 1993 a 1997 o grupo etário mais atingido foi o de 30 a 49 anos (39,33\%). Relatórios de exames parasitológicos da rede do Sistema Único de Saúde em 1990 e 1991 registraram 1.770 e 1449 casos de Taenia sp, correspondendo a 1,42\% do total de 257.588 exames realizados. No aspecto de saneamento ambiental não contam com uma solução coletiva e sanitariamente eficaz em termos de esgotos sanitários. A companhia de saneamento regional abastece apenas $9 \%$ das 3.400 localidades rurais do Estado. Outro agravante do ciclo de transmissão é que cerca de $70 \%$ da carne consumida não passa por qualquer controle sanitário. Segundo dados do Ministério da Agricultura do Brasil, cerca de 3 a $5 \%$ dos bovinos abatidos no país apresentam Cisticercose. A Suinocultura de subsistência registra índices superiores a $10 \%$ de positividade para Cisticercose em várias localidades do Paraná (Tijucas do Sul, Rio Branco do Sul entre outros projetos de pesquisa de prevalência). O Ministério da Saúde do Brasil ainda não contempla a Neurocisticercose como doença de notificação obrigatória. Material e Métodos: O Programa de Controle da Teníase e Cisticercose fundamentou-se a partir de projetos experimentais desenvolvidos em diversos municípios das regiões Centro-Sul e Norte do Paraná na década de 1980. Através da Resolução da SESA/ISEP No 19/94 institucionalizou-se o Programa Estadual de Controle da Teníase e Cisticercose, concretizando-se a operacionalização de diversas atividades: Vigilância Epidemiológica e Controle de Focos, com Mebendazol e Praziquantel. Instituição da Notificação Obrigatória da Cisticercose e Teníase Humanas. Tratamento em massa de 1.283.000 pessoas de cinco regionais da região Centro-Sul do Paraná (48 municípios), com campanhas educativas e distribuição de medicamentos casa à casa. Elaboração de um conjunto de instrumentos de educação em saúde (vídeo, slides, transparências, material científico, cartilhas, folhetos, cartazes, álbum seriado, etc). Desenvolvimento de tecnologia pelo Centro de Medicamentos do Paraná para produção de Mebendazol em larga escala e de Albendazol para futuros projetos; Implementação das técnicas de Imunofluorescência e Enzima-imunoensaio para diagnóstico imunológico humano e animal pelo Laboratório Central para fins de diagnóstico precoce; Otimização dos recursos públicos para diagnóstico por imagem; Produção de antígenos e antisoros específicos além de pesquisas científicas sobre o assunto no Centro de Produção de Imunobiológicos. Paralelamente, atuou-se também de 1988 a 1998 com a construção de 34.178 módulos sanitários em todo o Estado. A implantação de serviços regionais e municipais de inspeção de abatedouros contribuiu nos últimos anos para reduzir a problemática. Estratégias: A constituição de um grupo de trabalho (1992) com integrantes das áreas de saúde, universidades, meio ambiente e educação permitiu encontrar soluções apropriadas para o contexto a nível regional e local. Contou-se também com o apoio fundamental de setores como o militar e o da educação, em especial nas campanhas de tratamento em massa. Resultados: O Paraná conta com um trabalho consistente técnica e juridicamente. Duas medidas destacaram-se pela eficácia , ação sobre o agente etiológico e impacto a curto prazo no ciclo de transmissão: Controle de Focos e Tratamento em Massa. Experiência de tratamento em massa durante cinco anos semestral ou anualmente com Mebendazol, sem registro de qualquer ocorrência clínica; Domínio de tecnologia de produção de medicamentos específicos e produção de antígenos; Existência de reduzido e simplificado número de formulários que compõem o sistema de notificação; Mobilização de grande contingente de profissionais de saúde e voluntários na divulgação do problema e execução de companhas educativas. Conclusão: Existe um grande trabalho iniciado com muitas correções a se processarem, mas, a experiência do Paraná pode servir de modelo para outras unidades federadas para controlar o complexo Teníase/Cisticercose. 